\title{
Model for Assessment of Child Mortality under Different Parity: A Bayesian Swatch
}

\author{
Arunabh Tripathi', G. P. Singh ${ }^{2}$, Abhinav Singh ${ }^{3}$ \\ ${ }^{1}$ NIIMH, CCRAS, Ministry of AYUSH, Hyderabad, India \\ ${ }^{2}$ Department of Statistics and DST-CIMS, BHU, Varanasi, India \\ ${ }^{3}$ Department of Statistics, University of Allahabad, Allahabad, India \\ Email: ashoka07bhu@yahoo.in
}

How to cite this paper: Tripathi, A., Singh, G.P. and Singh, A. (2019) Model for Assessment of Child Mortality under Different Parity: A Bayesian Swatch. Journal of Biosciences and Medicines, 7, 113-126. https://doi.org/10.4236/jbm.2019.75014

Received: March 23, 2019

Accepted: May 17, 2019

Published: May 20, 2019

Copyright () 2019 by author(s) and Scientific Research Publishing Inc. This work is licensed under the Creative Commons Attribution International License (CC BY 4.0).

http://creativecommons.org/licenses/by/4.0/

\begin{abstract}
In this study a model is conceptualized to measure the child mortality under different parity of women such that a better strategy can be formulated to bring down mortality rates. In the estimation of probability of child mortality some socio demographic variables are taken in consideration. The estimates are obtained under Bayesian procedure. Two different models are formulated for it and model fitting is observed by graphical approach along with the chi square test. First model is beta-binomial and second is binomial regression model. Second model shows the better fit on the data. The estimate of probability of child mortality at higher parities namely, parity 3 , parity 4 and parity 5 were obtained as $0.06,0.09$ and 0.13 respectively on the basis of the second model.
\end{abstract}

\section{Keywords}

Child Mortality, Model Fitting, Bayesian Procedure

\section{Introduction}

Children are important assets of a nation and reduction in infant and child mortality is one of the key factors which are taken into consideration while planning for the growth of the nation. Child mortality is also a good indicator of level and quality of health care as well as socio-economic condition of community. Recognizing the important role that child health plays in the overall health of societies, the Millennium Development Goals include a goal explicitly aimed at reducing child mortality by two-thirds, between 1990 and 2015.

Child mortality, also known as under- 5 mortality, refers to the death of infants and children under the age of five. The trend in child mortality is declining 
over time but rate of decline is not fast. Child Mortality rate is the highest in low-income countries. Still many deaths in the third world go unnoticed since many poor families cannot afford to register their babies in the government registry.

Under five year mortality rate for the world was 91 per 1000 live birth in 1990 which decreased to 43 in 2015 (http://www.who.int/). The under five mortality for India was 126 in 1990 as compared to 48 in 2015 (http://www.childmortality.org/). No doubt there is significant reduction in child mortality in India but as per UNICEF report, India is still in the list of high child mortality countries.

The infant and child mortality studies have long been of interest to demographers and person concerned with public health problem. The most common problem in such studies is the error in data of deaths during infancy and childhood. In this condition, development of stochastic models is a good choice to minimize the effect of such errors.

Perhaps the first attempt to model the infant mortality was made by Keyfitz [1], after that many authors contributed towards modeling of infant and child mortality [2] [3] [4] [5] [6]. The estimation of model parameters in above mentioned studies were based on classical estimation techniques. The classical estimation technique serves a lot of properties and requires less computational skill but it is unable to find estimates under complex modeling situations. On the other hand, Bayesian estimation approach is capable of doing estimation in complicated situations and provides direct interpretation of results.

The availability of computers based computational technique; Bayesian method of estimation is getting popularity as well as acceptance in all modeling situations. Various authors have been used this technique in the estimation of infant and child mortality [7] [8] [9] [10] [11].

The key features of Bayesian modeling are the likelihood function, which reflects information about the parameters contained in the data, and the prior distribution, which quantifies what, is known about the parameters before observing data. The prior distribution and likelihood are further combined to get the posterior distribution of parameter, which represents total knowledge about the parameters after the data have been observed. Simple summaries of this distribution can be used to isolate quantities of interest and ultimately to draw substantive conclusions whereas the classical modelling approaches uses only the likelihood function and hence sampling distribution of estimator, which reflects information about the parameters contained in the data.

The present study is an attempt to model child death in such a way that we get estimate of child mortality according to the parity of mothers. The aim behind it was to provide a platform for monitoring agencies to re-plan their strategies for bringing faster decline in child mortality. In present study an attempt is also made to find out the relationship of different socio-economic variables with child mortality in total reproductive life span of women according to different parity. Two models have been taken into account to estimate the mortality rate 
among different parity.

\section{Method}

Let us consider the population of $N$ women who have given birth to $\mathrm{n}$ children during their reproductive period. Define a random variable $Z_{i j}(i=1,2, \cdots, N$ and $j=1,2, \cdots, n)$ as given below:

$$
Z_{i j}=\left\{\begin{array}{l}
1 \mid \text { if } j^{\text {th }} \text { child of } i^{\text {th }} \text { women dies } \\
0 \mid \text { if } j^{\text {th }} \text { child of } i^{\text {th }} \text { women survives }
\end{array}\right.
$$

Thus $Z_{i j}$ is a Bernoulli random variable. Further, we can define another random variable $Y_{i}(i=1,2, \cdots, N)$ such that

$$
Y_{i}=\sum_{j=1}^{n} Z_{i j}
$$

with possible values $0,1,2, \cdots, n$ and it shows the number of child death experienced by $i^{\text {th }}$ women. If we assume that deaths of children experienced by $i^{\text {th }}$ women are independent and with same unknown probability say $p_{i}$ then $Y_{i}$ assumed to follow binomial distribution. Here $n$ will denote parity (total children born in life span) of a women and let pi is probability of experiencing child death by $i^{\text {th }}$ women of parity $n$.

\subsection{Model-I}

The model -I is defined as below according to above explanation of the study:

Let

$$
f\left(Y_{i}\right)=C_{y_{i}}^{n} p_{i}^{y_{i}}\left(1-p_{i}\right)^{n-y_{i}}
$$

here $n$ denotes parity of women and we have considered $n=3,4$ and 5, $i$ denotes $\mathrm{i}^{\text {th }}$ women of parity $n(i-1,2, \cdots, N)$. The prior distribution for parameter $p_{i}$ is taken as beta distribution with probability density function:

$$
f\left(p_{i}\right) \propto p_{i}^{\alpha-1}\left(1-p_{i}\right)^{\beta-1}
$$

Combining it by Bayes theorem the posterior probability density function will have a beta distribution. We use non-informative beta $(1,1)$ prior which is flat and reflect no prior information regarding the parameter being estimated.

\subsection{Model-II}

In this model, while estimating the probability of child death to particular women the consideration of different socio-economic and demographic variables was incorporated in model. For each $\mathrm{n}(n=3,4,5)$ pi is unknown parameter of interest. Since $p_{i}$ is affected by various socio-economic variables. Then we consider pi as a function of a few explanatory variables $X_{m},(m=1, \cdots, 4)$ and propose to use generalized linear model(GLM). The general linear model (logit model) is popularly used to see the association between Bernoulli response variable and the factors affecting it. In modeling by general linear model, the 
dependent variable is transformed into continuous form by using link function. Dichotomous dependent variable like $Z_{i j}$ with probability of death of $f^{\text {th }}(i=1,2$, $\cdots, n)$ child born to $i^{\text {th }}(i=1,2, \cdots, N)$ women as $\mathrm{p}_{\mathrm{i}}$, a link function called logit link function is used to make dependent variable continuous. It is actually expected value of logarithm of odds of experiencing a child death to not experiencing a child death. Thus GLM defines the relationship as

$$
\log \text { it }\left(p_{i}\right)=\log \left(\frac{p_{i}}{1-p_{i}}\right)
$$

Now

$$
\log \left(\frac{p_{i}}{1-p_{i}}\right) \sim N\left(\mu_{i}, \sigma^{2}\right)
$$

Thus expected value of $\log$ it $\left(p_{i}\right)=\mu_{i}$ and if we take

$$
\mu_{i}=\beta_{0}+\beta_{1} X_{1}+\beta_{2} X_{2}+\cdots+\beta_{p} X_{p} .
$$

So,

$$
\log \operatorname{it}\left(p_{i}\right)=\beta_{0}+\beta_{1} X_{1}+\beta_{2} X_{2}+\cdots+\beta_{p} X_{p}
$$

where, $X_{1}, X_{2}, \cdots, X_{p}$ (generally called explanatory variables) are the variables associated with $\log$ it $\left(p_{i}\right)$ known as logistic regression.

The unknown regression coefficients in (4) are $\beta_{0}, \beta_{1}, \beta_{2}, \cdots, \beta_{p}$ which are estimated from the data and for the Bayesian approach they are estimated from their joint posterior distribution. The proposed model is linear for the regression coefficients on the logit scale.

In present study four explanatory variables are taken for the estimation of probability of child death experienced by women. The four explanatory variables are age at first birth $\left(X_{1}\right)$, education of mother $\left(X_{2}\right)$, religion $\left(X_{3}\right)$ and type of house $\left(X_{4}\right)$. The variable $X_{1}$ quantitative and continuous in nature and measured in years, and $X_{2}, X_{3}, X_{4}$ are categorical variables. $X_{2}$ has four levels as illiterate, primary, middle and above middle. There are two levels of $X_{3}$ as Hindu and non-Hindu. Finally the fourth explanatory variable $X_{4}$ has three levels as kaccha, semi pucca and pucca. Thus the proposed model is:

$$
\operatorname{logit}\left(p_{i}\right)=\beta_{0}+\beta_{1} X_{1}+\beta_{2} X_{2}+\beta_{3} X_{3}+\beta_{4} X_{4}
$$

where,

$$
p_{i}=\frac{\exp \left(\beta_{0}+\beta_{1} X_{1}+\beta_{2} X_{2}+\beta_{3} X_{3}+\beta_{4} X_{4}\right)}{1+\exp \left(\beta_{0}+\beta_{1} X_{1}+\beta_{2} X_{2}+\beta_{3} X_{3}+\beta_{4} X_{4}\right)}
$$

Further, for the Bayesian analysis, priors are required for all the parameters before data in hand.

In present study independent non-informative priors have been used considering that we have no strong a priori idea about regression parameters and hence following prior distribution is considered:

$$
p\left(\beta_{i}\right)=\frac{1}{\sqrt{2 \pi \sigma^{2}}} \mathrm{e}^{-\frac{1}{2 \sigma^{2}}\left(\beta_{i}-\bar{\beta}\right)^{2}} \text { if }-\infty \leq \beta_{i} \leq \infty
$$


for $i=1,2,3$ and 4 . We put $\bar{\beta}=0$ and $\sigma^{2}=\frac{1}{0.0001}$ which shows a negligible faith on prior knowledge and has uniform type shape. Further, suppose that we draw the random samples from binomial distribution then the joint probability function can be written as $p\left(y \mid \beta_{0}, \beta_{1}, \beta_{2}, \beta_{4}\right)$ and thus the joint posterior distribution can be obtained as:

$$
p\left(\beta_{0}, \beta_{1}, \beta_{2}, \beta_{4} \mid y\right) \frac{p\left(\beta_{m}\right) p\left(y \mid \beta_{m}\right)}{\int p\left(\beta_{m}\right) p\left(y \mid \beta_{m}\right) d \beta_{m}}
$$

After obtaining the posterior distribution of regression coefficients we obtain the Bayesian estimate of regression coefficients from this distribution under squared error loss function with use of Monte Carlo Markov Chain process. Here Gibbs sampling procedure is used for this purpose.

\subsection{Data}

To check the suitability of proposed methodology in estimating the situation of child mortality, data was taken from District Level Household and Facility Survey (DLHS-3, 2007-2008) [12]. A multi-stage stratified systematic sampling design was adopted in DLHS-3. In each district of country, 50 Primary Sampling Units (PSUs) which were census villages for rural areas and wards for urban areas were selected in the first stage by systematic Probability Proportional to Size (PPS) sampling. DLHS-3 questionnaires were canvassed from 7, 20, 320 households, 6, 43, 944 ever-married women aged 15 - 49 years and 1, 66, 260 unmarried women aged 15 - 24 years. From DLHS-3 data $(6,43,944$ ever-married women), the state of Uttar Pradesh was chosen for the analysis. Uttar Pradesh is the most populous state in India.

Table 1 presents the data of mothers who have completed their fertility life and experienced any number of child death in complete span of fertility life. It is to mention that the completion of fertility life span was decided by the questions asked in survey. The women having the responses "no" on the question of further desire of child were considered as the women with completed fertility life span. These women were further divided among parities like women with $0,1,2$, $3,4,5,6$, etc. parity, on every parity the numbers of women were counted who experienced different numbers of death. To explore the suitability of proposed model, only parity 3, 4 and 5 were considered in present study because 3,4 and 5 are most common parity in selected population. Parity is defined as the number of live birth to a woman in her fertility life span.

Table 1 reveals that there were 6688, 6246 and 5340 women at parity 3; parity 4 and parity 5 respectively in Uttar Pradesh who found have completed fertility life span. Out of 6688 women of parity 3, 1153 experienced child death which was about $17 \%$, similarly the data reveals that $32 \%$ of the women experienced at least one child death at parity 4 . However, women of parity 5 experienced highest child death which was about $48 \%$ (2551). 
Table 2 describes the distribution of women according to different explanatory variables taken in consideration for the estimation association of child death. Table 2 showed that out of 6688 women of parity 3, 3429 were illiterate; however, among literate women 939, 1017 and 1303 were having education up to primary, middle and above middle respectively. Among the women of parity 3, 5766 were Hindu and 1592, 3117 and 1979 were found to having kaccha, semi pucca and pucca house respectively. At parity 4, 4064 were illiterate, 898 attain primary, 675 were having education up to middle and 609 women had higher education. Out of all women of parity 4, 5109 were Hindu while 1137 were non-Hindu, further 1720 women were living in kaccha house, 3089 women in semi pucca and 1437 women were living in pucca house. Among the women of parity 5, 3946, 669, 452 and 273 were education level as illiterate, primary, middle and above middle respectively. 4184 women were Hindu while 1156 women were non-Hindu. In context of residential accommodation, 1600, 2750 and 990 women found to reside in kaccha, semipucca and pucca houses respectively. The distribution in Table 2 showed a decreasing trend in level of education when the parity of women increases. Most of the women found to reside in semipucca houses and belong to Hindu community.

Table 1. Distribution of women taken from DLHS-3 data with parity.

\begin{tabular}{|c|c|c|c|c|c|c|c|}
\hline \multirow{2}{*}{ Parity } & \multicolumn{6}{|c|}{ Number (\%) of Child Death } & \multirow{2}{*}{ Total } \\
\hline & 0 & 1 & 2 & 3 & 4 & 5 & \\
\hline 3 & $\begin{array}{c}5535 \\
(82.76 \%)\end{array}$ & $\begin{array}{c}1083 \\
(16.19 \%)\end{array}$ & $\begin{array}{c}68 \\
(1.02 \%)\end{array}$ & $\begin{array}{c}2 \\
(0.03 \%)\end{array}$ & - & - & $\begin{array}{c}6688 \\
(100 \%)\end{array}$ \\
\hline 4 & $\begin{array}{c}4259 \\
(68.19 \%)\end{array}$ & $\begin{array}{c}1669 \\
(26.72 \%)\end{array}$ & $\begin{array}{c}296 \\
(4.74 \%)\end{array}$ & $\begin{array}{c}22 \\
(0.35 \%)\end{array}$ & 0 & - & $\begin{array}{c}6246 \\
(100 \%)\end{array}$ \\
\hline 5 & $\begin{array}{c}2789 \\
(52.23 \%)\end{array}$ & $\begin{array}{c}1839 \\
(34.44 \%)\end{array}$ & $\begin{array}{c}570 \\
(10.7 \%)\end{array}$ & $\begin{array}{c}125 \\
(2.33 \%)\end{array}$ & $\begin{array}{c}17 \\
(0.3 \%)\end{array}$ & 0 & $\begin{array}{c}5340 \\
(100 \%)\end{array}$ \\
\hline
\end{tabular}

Table 2. Parity wise distribution of women on selected explanatory variable.

\begin{tabular}{ccccccc}
\hline \multirow{2}{*}{ Education } & \multicolumn{2}{c}{ Parity 3 } & \multicolumn{2}{c}{ Parity 4 } & \multicolumn{2}{c}{ Parity 5 } \\
\cline { 2 - 6 } & No & $\%$ & No & $\%$ & No & $\%$ \\
\hline Illiterate & 3429 & 51.3 & 4064 & 65.1 & 3946 & 73.9 \\
Primary & 939 & 14.0 & 898 & 14.4 & 669 & 12.5 \\
Middle & 1017 & 15.2 & 675 & 10.8 & 452 & 8.5 \\
Above Middle & 1303 & 19.5 & 609 & 9.8 & 273 & 5.1 \\
Religion & & & & & & \\
Hindu & 5766 & 86.2 & 5109 & 81.8 & 4184 & 78.4 \\
Non Hindu & 922 & 13.8 & 1137 & 18.2 & 1156 & 21.6 \\
Type of house & & & & & & 30.0 \\
Kaccha & 1592 & 23.8 & 1720 & 27.5 & 1600 & 51.4 \\
Semi Pucca & 3117 & 46.6 & 3089 & 49.5 & 2750 & 990 \\
Pucca & 1979 & 29.6 & 1437 & 23.0 & & 18.6 \\
\hline
\end{tabular}




\subsection{Analysis}

The Bayesian analysis of both of the proposed models was performed on the basis of data given in Table 1 and Table 2 for each parity separately on WinBUGS software. To obtain the Bayes estimates of parameters of the models described in Equation (6) a programme was written in the language of WinBUGS. After running this programme in WinBUGS we summarize the estimates after discarding 20,000 initial updates. Thus 40,000 updates were run after the initial burn in and MC error for each parameter was less than $5 \%$ of its standard deviation. In addition to controlled MC error, the Kernel density of each parameter was also found to be well in normal shape. After being confirmed with all the diagnostic about convergence of the parameters, the estimates were obtained.

\section{Results}

The results obtained from proposed model-I was tested for its fit by the help of graphs of observed frequency of death and expected frequency of death for each parity. Figure 1 shows the fit of parity 3, parity 4 and parity 5 respectively. It is clear that model-I is unable to capture the uncertainty among deaths of children of a mother of each considered parity. Apart from graphical fitting, an attempt was also made to check the fitting by calculating chi-square values for considered parity. The results are shown in Table 3. Table 3 shows that the model-I lacks the fit. The estimate of probability of child death by this model is $0.24,0.23$ and 0.23 at parity 3 , parity 4 and parity 5 respectively. Since this model was not suitable for the estimation so the suitability of model-II was assessed further. Figure 2 shows the graphical representation of model fit in case of model-II. The model fit graph for each parity shows a close fit evidence of model-II. The expected child death and chi square calculations for considered parities are given in Table 4. Table 4 also gave indication of model fit. The estimate of child mortality at parity 3, parity 4 and parity 5 was obtained as $0.06,0.09$ and 0.13 respectively from model-II. In other words out of 100 birth 6,9 , and 13 child deaths are being observed at different parity of women. It shows that the risk of mortality go higher as the parity of women become higher. The regression coefficients and odds ratio based on model-II were further calculated with the highest posterior density intervals. As mentioned earlier the analysis was done in WinBUGS software which is able to calculate directly posterior distribution of parameters i.e., for regression coefficients with use of Monte Carlo Markov Chain process. The WinBUGS programme developed to estimate the parameter of proposed model. The estimate of regression coefficient $(\beta \mathrm{s})$ with its standard deviation (SD) and central $90 \%$ highest probability Density (HPD) interval are calculated in WinBUGS and on the basis of $\beta$ s coefficient we calculate odds ratio. The results are presented in Table 5, Table 6 and Table 7 for considered parity 3, parity 4 and parity 5 respectively. 
Table 3. Model fitting and estimate of mortality under Model-I.

\begin{tabular}{ccccccc}
\hline \multirow{2}{*}{ No. of Death } & \multicolumn{2}{c}{ Parity 3} & \multicolumn{2}{c}{ Parity 4 } & \multicolumn{2}{c}{ Parity 5 } \\
\cline { 2 - 7 } & Obs & Exp & Obs & Exp & Obs & Exp \\
\hline $\mathbf{0}$ & 5535 & 3480 & 4259 & 2866 & 2789 & 2098 \\
$\mathbf{1}$ & 1083 & 1971 & 1669 & 1786 & 1839 & 1464 \\
$\mathbf{2}$ & 68 & 935 & 296 & 994 & 570 & 933 \\
$\mathbf{3}$ & 2 & 303 & 22 & 458 & 125 & 526 \\
$\mathbf{4}$ & & NA & 0 & 141 & 17 & 243 \\
$\mathbf{5}$ & & NA & & NA & 0 & 76 \\
Total & 6688 & 6688 & 6246 & 6246 & 5340 & 5340 \\
Prob. of Death & & 0.24 & & 0.23 & & 0.23 \\
$\chi^{2}$ Value & & 2715.85 & & 1731.80 & & 1056.43 \\
\hline
\end{tabular}

Table 4. Model fitting and estimate of mortality under Model-II.

\begin{tabular}{ccccccc}
\hline \multirow{2}{*}{ No. of Death } & \multicolumn{2}{c}{ Parity 3 } & \multicolumn{2}{c}{ Parity 4 } & \multicolumn{2}{c}{ Parity 5 } \\
\cline { 2 - 7 } & Obs & Exp & Obs & Exp & Obs & Exp \\
\hline $\mathbf{0}$ & 5535 & 5544 & 4259 & 4257 & 2789 & 2795 \\
$\mathbf{2}$ & 1083 & 1066 & 1669 & 1682 & 1839 & 1818 \\
3 & 68 & 76 & 296 & 283 & 570 & 591 \\
4 & 2 & 2 & 22 & 24 & 125 & 119 \\
5 & & NA & 0 & 1 & 17 & 15 \\
Total & & NA & & NA & 0 & 1 \\
Prob. of Death & 6688 & 6688 & 6246 & 6247 & 5340 & 5339 \\
$\chi^{2}$ Value & & 0.06 & & 0.09 & & 0.13 \\
& & 1.09 & & 1.76 & & 2.56 \\
\hline
\end{tabular}

Table 5. Estimates of association of different variables with child mortality (Parity 3).

\begin{tabular}{|c|c|c|c|c|c|}
\hline & \multicolumn{4}{|c|}{ HPD intervals } & \multirow{2}{*}{ Odds ratio } \\
\hline & Estimate of $\beta$ & $\mathrm{SD}$ & $5.00 \%$ & $95.00 \%$ & \\
\hline Intercept & -3.014 & 0.1769 & -3.314 & -2.733 & \\
\hline AFB & -0.00783 & 0.07521 & -0.1306 & 0.1148 & 0.9922006 \\
\hline \multicolumn{6}{|l|}{ Education } \\
\hline Illiterate & 0.3908 & 0.2072 & 0.04988 & 0.7258 & 1.4781629 \\
\hline Primary & 0.1826 & 0.2477 & -0.2321 & 0.5934 & 1.2003342 \\
\hline Middle & 0.3621 & 0.2318 & -0.0242 & 0.7487 & 1.4363426 \\
\hline \multicolumn{6}{|l|}{ Religion } \\
\hline Non Hindu & -0.4745 & 0.1779 & -0.771 & -0.1779 & 0.6221961 \\
\hline \multicolumn{6}{|l|}{ Type of House } \\
\hline Kaccha & -0.2353 & 0.291 & -0.7336 & 0.2247 & 0.7903337 \\
\hline Semipucca & 0.07917 & 0.1549 & -0.1753 & 0.3339 & 1.0823883 \\
\hline
\end{tabular}


A. Tripathi et al.

Table 6. Estimates of association of different variables with child mortality (Parity 4).

\begin{tabular}{|c|c|c|c|c|c|}
\hline & \multicolumn{4}{|c|}{ HPD intervals } & \multirow{2}{*}{ Odds ratio } \\
\hline & Estimate of $\beta$ & SD & $5.00 \%$ & $95.00 \%$ & \\
\hline Intercept & -2.354 & 0.0823 & -2.49 & -2.223 & \\
\hline AFB & 0.1155 & 0.02163 & 0.07997 & 0.1513 & 1.1224345 \\
\hline \multicolumn{6}{|l|}{ Education } \\
\hline Illiterate & 0.07167 & 0.08058 & -0.0628 & 0.2049 & 1.0743008 \\
\hline Primary & 0.004913 & 0.09589 & -0.1544 & 0.1624 & 1.0049251 \\
\hline Middle & 0.004717 & 0.101 & -0.1629 & 0.1731 & 1.0047281 \\
\hline \multicolumn{6}{|l|}{ Religion } \\
\hline Non Hindu & -0.4465 & 0.06618 & -0.5566 & -0.3367 & 0.6398638 \\
\hline \multicolumn{6}{|c|}{ Type of House } \\
\hline Kaccha & 0.09936 & 0.06672 & -0.0102 & 0.2076 & 1.1044638 \\
\hline Semipucca & 0.05445 & 0.05913 & -0.0435 & 0.1524 & 1.0559597 \\
\hline
\end{tabular}

Table 7. Estimates of association of different variables with child mortality (Parity 5).

\begin{tabular}{|c|c|c|c|c|c|}
\hline & \multicolumn{4}{|c|}{ HPD intervals } & \multirow{2}{*}{ Odds ratio } \\
\hline & Estimate of $\beta$ & $\mathrm{SD}$ & $5.00 \%$ & $95.00 \%$ & \\
\hline Intercept & -2.125 & 0.09566 & -2.281 & -1.969 & \\
\hline AFB & 0.02462 & 0.01966 & -0.0080 & 0.05772 & 1.0249256 \\
\hline \multicolumn{6}{|l|}{ Education } \\
\hline Illiterate & 0.03906 & 0.09447 & -0.1169 & 0.1939 & 1.0398329 \\
\hline Primary & 0.01981 & 0.1072 & -0.1538 & 0.1963 & 1.0200075 \\
\hline Middle & 0.08063 & 0.1134 & -0.1124 & 0.2649 & 1.0839698 \\
\hline \multicolumn{6}{|l|}{ Religion } \\
\hline Non Hindu & -0.3955 & 0.05367 & -0.4827 & -0.3083 & 0.6733433 \\
\hline \multicolumn{6}{|l|}{ Type of House } \\
\hline Kaccha & 0.2454 & 0.06245 & 0.1416 & 0.3483 & 1.2781325 \\
\hline Semipucca & 0.172 & 0.0563 & 0.08093 & 0.2656 & 1.1876778 \\
\hline
\end{tabular}

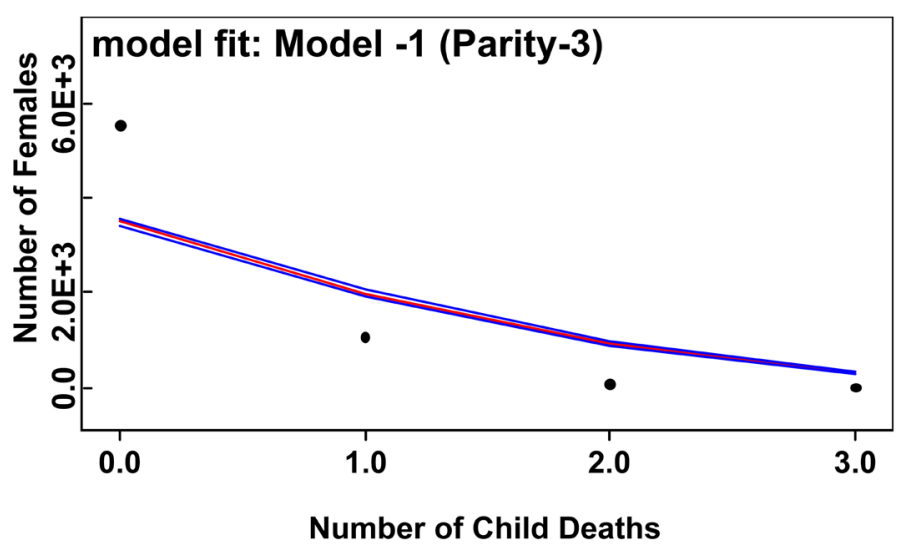



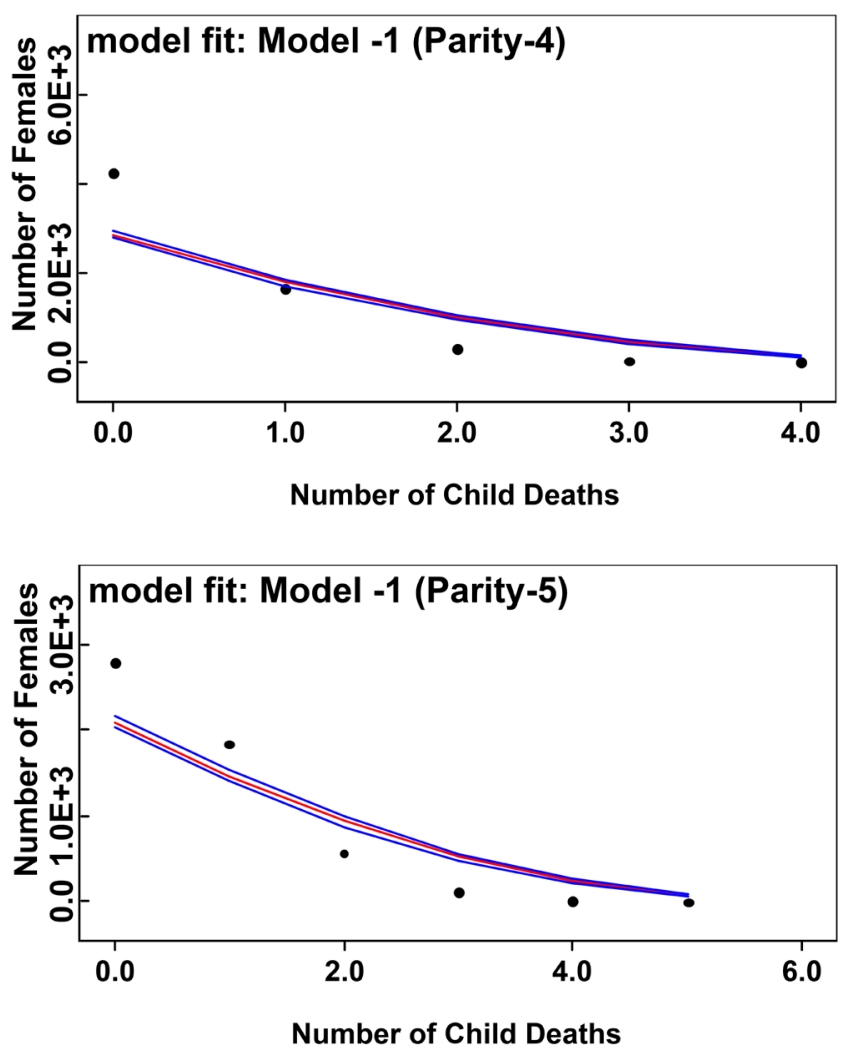

Figure 1. Graph of model fit of model-I for different parity. Dot represents observed count. Red line showing fitted model and blue lines show 95\% HPD.
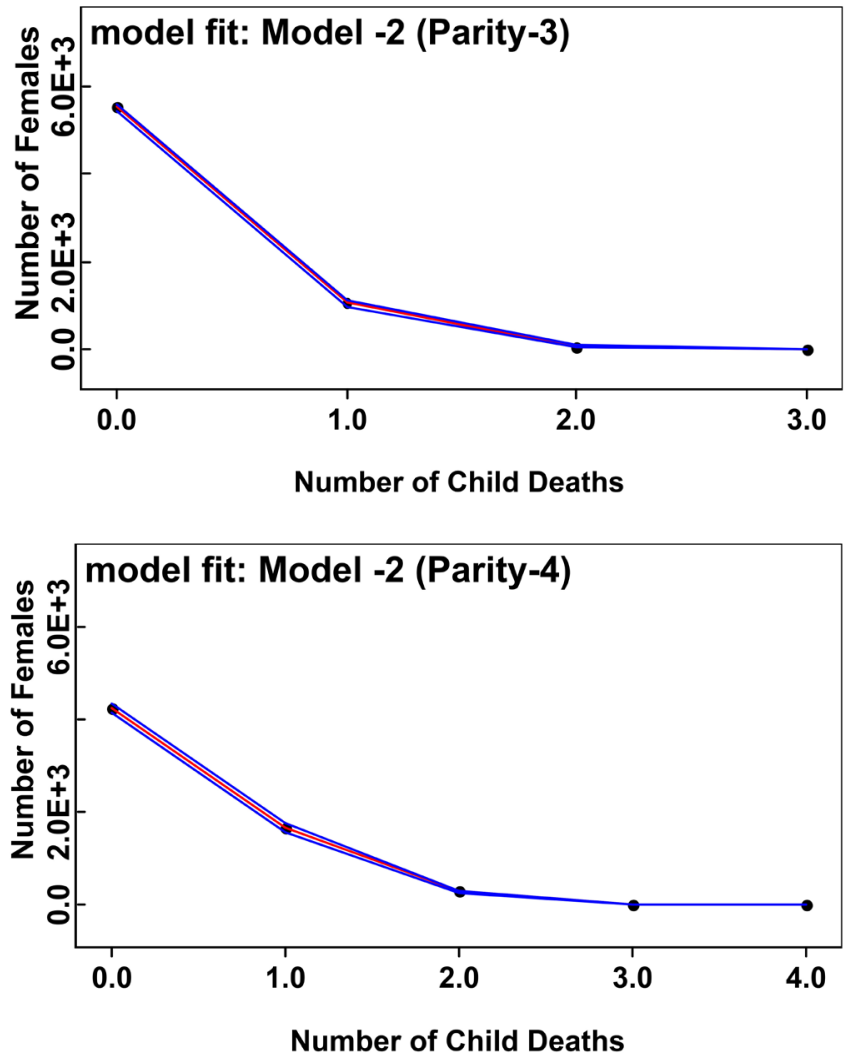


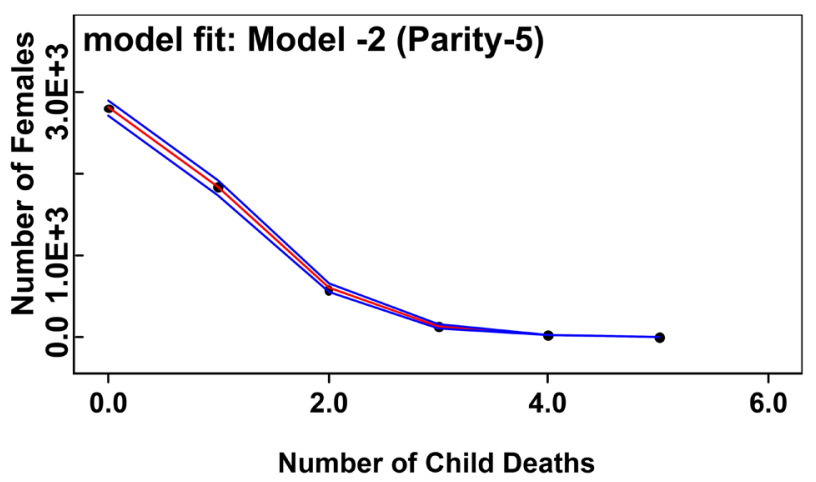

Figure 2. Graph of model fit of model-II for different parity. Dot represents observed count. Red line showing fitted model and blue lines show 95\% HPD.

Table 5 shows that the regression coefficient of AFB is negative for parity 3 but this value is very small $(-0.00783)$, and HPD interval nearly covers equal area on both sides of 0 value $(-0.1306,0.1148)$. For the variable mother education all the three lower categories' regression coefficient are positive when the highest education category of mother is taken as reference category. The odd of child mortality is highest in illiterate category (1.47) and the 90\% HPD interval for this regression coefficient comes under between 0 and above. The odds ratio for non Hindu is 0.62 as compared to Hindu which shows that Hindu has higher risk of child death as compared to other religions which are prevailing in Uttar Pradesh. The variable type of house does not give any clear pattern in determining child mortality.

Table 6 describes the regression analysis for parity 4 . The continuous variable AFB shows the positive regression coefficient with $90 \%$ HPD interval in positive. The odd of child mortality is higher by 1.12 times in unit increase in AFB as compared to mean level of AFB. Education status of mother shows that with decreasing of mother educational category the risk of child mortality becomes higher. But this result is not so conclusive because the magnitude and variation of regression coefficients are not strong. Again in parity 4 Hindu has higher risk of child mortality nearly in same magnitude as present in parity 3 . The regression coefficient for kaccha (0.099) and semi-pucca (0.054) houses are positive though their 90\% HPD intervals do not support these finding for conclusive statement.

For parity 5, the outcome of regression analysis is mentioned in Table 7. The table shows there is no role of AFB in child mortality determination. The negative association was found between mother education and child mortality which finding also exist in parity 3 and parity 4 as well. The finding for Hindu females remains same and having higher chance of experiencing child mortality. It is also see by table that the female belonging to pucca house has lesser chance of child mortality as compared to kachha and semipucca house.

\section{Discussions}

The aim of present study was to find out valid estimate of relationship between 
child mortality and selected socio-economic variable through mathematical modelling. Generalized linear model is used in Bayesian setup for this purpose, where risk of death was dependent on selected socio-economic factors. Data were used from DLHS-3 for UP state. Factors like education of mother were found decreasing effect on the risk of child death which is not significant but various studies have supported a direct causal relationship between mother's education and child mortality [3] [13]. This is due to the division of data on the basis of parity or due to consideration of total reproductive life span of women. The factor religion shows significant increasing risk of child death in Hindus as compared to other religions. This result is quite hesitating to explain and no one can give a strong argument that, why this result occurred but it gave implication that Hindus are at higher risk of child mortality in comparison of other religion so a separate plan for Hindu's family are essential for reducing child mortality and it is also a point to think that the majority of this state is still have higher risk of child death. Although this finding supported by Bhalotra [14]. Bhalotra explored this hypothesis by using information reported by mothers on ideal family composition. They recognize, however, that adding this variable in their analyses does not shed more light on the Muslim mortality advantage. Nonetheless, they conclude that this may be due to data limitations and argue that this is a dimension of the Muslim mortality paradox that is worth exploring further. Geruso and Spears [15] also conclude "In India, Muslims face significantly lower child mortality rates than Hindus, despite Muslim parents being poorer and less educated on average. Because observable characteristics would predict a Muslim disadvantage relative to Hindus, previous studies documenting this robust and persistent pattern have called it a 'puzzle' of Muslim mortality'. Basu et al. [16] much-explored demographic relationship between fertility and child survival, they explain that "one would expect infant and child mortality to be higher among Muslims than Hindus in India. This expectation is buttressed by the fact that Muslim women also display so many of the other features of high mortality situations-relatively low levels of education, greater conservatism in medical matters, higher levels of poverty. And yet, the National Family Health Survey finds that infant and child mortality rates in India are significantly lower among Muslims. These results are intriguing not only because they fly against the expectations based on religious differentials in bio-demographic factors like parity and birth-spacing. They are surprising because, at least in the binary tables, they do not correlate particularly strongly with many of the other proximate determinants of infant and child mortality; determinants like ante-natal care, delivery conditions, exposure to infections and treatment of illness". Maitra [17] and Kravdal [18] briefly note that Muslims have lower mortality than Hindus, but do not address why that is the case. This issue quite complicated to explain, a detailed study is needed on that topic. The various studies already mentioned the child survival benefit in context of child mortality and infant mortality analysis by religion but these puzzles not specified for studies where child mortality for 
women considers for total reproductive life span. This is again a point of research in child mortality.

The factor type of house has no significant effect for parity-3, 4 but for parity 5 it shows significant effect. But there are various studies on infant or child mortality namely Gyimah [19], Hill [20] and Godson [21] in which generalized linear models (GLM) are used to find the factors related to infant or child mortality. According to above mentioned studies, mother education, birth order, and mother's age, type of locality, socioeconomic status and health facilities are found as the determinants of child or infant mortality. But in above mentioned study's authors were used the data of child mortality for some limited reproductive period of women and total reproductive life span of women was not studied.

\section{Conflicts of Interest}

The authors declare no conflicts of interest regarding the publication of this paper.

\section{References}

[1] Keyfitz, N. (1977) Introduction to the Mathematics of the Population with Revisions. Addition-Wesley Publishing Company, Boston.

[2] Cheo, M.K. (1981) Fitting of Age Pattern of Infant and Child Mortality with the Weibull Survival Function. Asian and Pacific Census Forum, 7, 10-13.

[3] Hobcraft, J.N., Mc Donald, J.W. and Rustein, S.O. (1984) Socio-Economic Factors in Child Mortality, a Cross-National Comparison. Population Studies, 38, 193-223. https://doi.org/10.1080/00324728.1984.10410286

[4] Krishnan, P. and Jin, Y. (1993) A Statistical Model for Infant Mortality. Janasamkhya, 11, 67-71.

[5] Singh, K.K., Pandey, N. and Gautam, A. (2008) A Probability Model for Describing the Distribution of Child Death and Its Application. In: Singh, K.K., Yadava, R.C. and Pandey, A., Eds., Population Poverty \& Health: Analytical Approaches, Hindustan Publishing Corporation (India), New Delhi, 146-155.

[6] Uddin, J., et al. (2008) Child Mortality in a Developing Country: A Statistical Analysis. Journal of Applied Quantitative Methods, 4, 271-283.

[7] Bhattacharyya, R. and Rao, A.S.R.S. (2009) Estimation and Analysis of Child Mortality for Indian States through a Bayesian Approach. https://paa2010.princeton.edu/papers/101457

[8] Gemperli, A. (2004) Spatial Patterns of Infant Mortality in Mali: The Effect of Malaria Endemicity. American Journal of Epidemiology, 159, 64-72. https://doi.org/10.1093/aje/kwh001

[9] Kandala, et al. (2002) Geo-Additive Models of Child Hood under Nutrition in Three Sub Saharan African Countries. SFB 386, Discussion Paper-287, University of Munich, Munich. https://doi.org/10.2139/ssrn.321043

[10] Koissi, M.C. and Hogan's, G. (2005) Using WinBUGS to Study Family Frailty in Child Mortality with an Application to Child Survival in Ivory Coast. African Population Studies, 20, 1-27. https://doi.org/10.11564/20-1-384

[11] Rahul, et al. (2007) Population Projection of India Using MCMC Technique: A WinBUGS Implementation. Demography India, 36, 145-154. 
[12] International Institute for Population Sciences on Sample Basis (2007-2008) DLHS-3 District Level Health Survey.

[13] Hossain, M.Z., Yadva, K.N.S. and Hossain, M.K. (2002) Determinants of Infant and Child Mortality in Bangladesh. Journal of Statistical Studies, 22, 1-12.

[14] Bhalotra, et al. (2010) The Puzzle of Muslim Advantage in Child Survival in India. Journal of Health Economics, 29, 191-204. https://doi.org/10.1016/j.jhealeco.2009.11.002

[15] Geruso, M. and Spears, D. (2014) Sanitation and Health Externalities: Resolving the Muslim Mortality Paradox. Working Paper, University of Texas, Austin.

[16] Basu, A.M., et al. (2007) Religious Differentials in Child Survival in India: Some Unexpected Findings. Annual Meeting of the Population Association of America, New York, 30 March 2007. https://paa2007.princeton.edu/docs/PAA2007PreliminaryProgram.pdf

[17] Maitra, P. (2004) Parental Bargaining, Health Inputs and Child Mortality in India. Journal of Health Economics, 23, 259-291. https://doi.org/10.1016/j.jhealeco.2003.09.002

[18] Kravdal, O. (2004) Child Mortality in India: The Community Level Effect of Education. Population Studies, 58, 177-192. https://doi.org/10.1080/0032472042000213721

[19] Gyimah, S.O. (2002) Ethnicity and Infant Mortality in Sub Saharan Africa: The Case of Ghana. Discussion Paper No. 02-10, Population Studies Centre, University of Western Ontario, London.

[20] Hill, A. (1991) Infant and Child Mortality: Levels, Trends and Data Deficiencies. In: Diseases and Mortality in Sub Saharan Africa, Oxford University Press, Oxford, 37-74.

[21] Godson, M.C. and Nnamedi, M.J. (2012) Environmental Determinants of Child Mortality in Nigeria. Journal of Sustainable Development, 5, 65-75. https://doi.org/10.5539/jsd.v5n1p65 